\title{
THE NATURAL HISTORY AND PROGNOSIS OF INFANTILE IDIOPATHIC SGOLIOSIS
}

\author{
J. C. Scott ANd T. H. Morgan*, Oxford, ENGland \\ From the Nuffield Orthopaedic Centre, Oxford
}

In recent years attempts to increase our knowledge of scoliosis, with special reference to the prognosis, have been principally centred on the interpretation and analysis of curve patterns (Ponseti and Friedman 1950, James 1951, 1954). But the normal variations between curves of similar pattern are sufficient to suggest that other aspects of the natural history are equally, if not more, important in assessing the prognosis, which is the principal concern of this paper.

One teaching in scoliosis is that the younger the curve starts the worse it will be when the patient is fully grown. This is in some respects fallacious but it is sufficient justification for focusing attention on infantile scoliosis.

Harrenstein (1936) coined the term " infantile " scoliosis and reported thirty-three cases. He emphasised the importance of early treatment and also observed that in one untreated case spontaneous recovery took piace after four years.

In 1951 James described as a clinical entity infantile idiopathic scoliosis. He defined it as " a dorsal scoliosis, present before the age of three, more frequent in boys than girls, with the apex to the left, and progressing to a severe deformity." Although our use of the term as the title of this paper indicates our acceptance of this type of scoliosis as a clinical entity, we differ on some minor aspects of natural history, and for the purpose of this analysis we have accepted as "infantile" curves present at the age of two. The acceptance of this age of onset minimises the accidental inclusion of acquired conditions of known etiology. Progressive infantile idiopathic scoliosis is an appropriate name for this type to differentiate it from the less frequent type in which spontaneous recovery takes place, for which we suggest the name resolving infantile idiopathic scoliosis.

\section{PROGRESSIVE INFANTILE IDIOPATHIC SCOLIOSIS}

Material-From 1,200 patients with scoliosis seen at the Wingfield-Morris Orthopaedic Hospital between 1922 and 1952, 218 patients with progressive idiopathic scoliosis were selected for analysis, the selection being based on suitable records and an adequate period of observation. From the analysis we have identified twenty-eight with progressive infantile idiopathic scoliosis. Radiographs taken before the age of two are available in most, and in the remainder there is reliable evidence that the curve was present at that age.

It is of interest to note the lack of reference to this type of scoliosis in American literature. We reproduce in Table I an analysis of $\mathbf{4 0 4}$ cases of scoliosis, of unspecified etiology, reported in 1941 by the Research Committee of the American Orthopaedic Association; our own figures are included in the Table for comparison.

A striking difference is evident. Whereas progressive infantile idiopathic scoliosis $(0-2)$ is represented by twenty-eight cases $(12 \cdot 8$ per cent) in our series, only one case was reported in the American series. This group was thus fifty times more common in our analysis. That this difference is real is supported by James (1951) who described thirty-three cases $(9 \cdot 3 \mathrm{per}$ cent) of infantile idiopathic scoliosis (age group 0-3) in a total series of 353 cases of scoliosis. It seems that in America this particular type of scoliosis is either rare, incompletely recognised, or confused with congenital scoliosis. It seems unlikely that it exists unrecognised because in our series the average age at diagnosis was only fifteen months, and in the American series reproduced above scoliosis with an onset before the age of five years represented only 1 per

* The Lord Nuffield Scholar in Orthopaedic Surgery 1952-53. 
cent of the total. To label this type congenital scoliosis would be incorrect, because in no case were there congenital defects visible on radiographs, and as will be shown later the rates of progression are significantly different.

Our twenty-eight patients have been observed for an average of twelve years. Twelve patients were subjected to operations at varying ages; but since we wish to consider first

TABLE I

AgE INCIDENCE OF SCOLIOSIS

\begin{tabular}{|c|c|c|c|c|}
\hline \multirow{2}{*}{$\begin{array}{l}\text { Age at } \\
\text { onset } \\
\text { (years) }\end{array}$} & \multicolumn{2}{|c|}{$\begin{array}{c}\text { Research Committee of the } \\
\text { American Orthopaedic Association } \\
(404 \text { cases })\end{array}$} & \multicolumn{2}{|c|}{$\begin{array}{c}\text { Our series } \\
\text { (218 idiopathic cases) }\end{array}$} \\
\hline & Number & Per cent & Number & Per cent \\
\hline () 2 & 1 & 0.25 & 28 & $12 \cdot 8$ \\
\hline $3-10$ & 63 & $15 \cdot 5$ & 30) & $13 \cdot 5$ \\
\hline 1120 & 340 & $84 \cdot 25$ & 160 & 73.7 \\
\hline
\end{tabular}

the progression of the disease exclusive of operative treatment, curve measurements after these operations have been excluded from this part of the analysis (Table II).

From this analysis we can observe several features peculiar to this type of scoliosis. 1) There is no sex differentiation, which is in contrast to scoliosis starting after the age of two,

TABLE II

Analysis of Twenty-eight Cases of Progressive Infantile Idiopathic Scoliosis

\begin{tabular}{|c|c|c|c|c|c|c|}
\hline \multicolumn{3}{|r|}{14 males. } & \multicolumn{4}{|l|}{14 females } \\
\hline Thoracic curve & . & . & . & . & . & . 25 \\
\hline \multicolumn{2}{|c|}{ Thoraco-lumbar curve. } & . & . & . & . & 3 \\
\hline \multicolumn{3}{|c|}{ Proportion of cases with apex to left } & . & . & . & . 93 per cent \\
\hline Shortest curve & . & . & . & . & . & . 3 vertebrae \\
\hline Longest curve & . & . & . & . & . & . 8 vertebrae \\
\hline \multicolumn{4}{|c|}{ Average number of vertebrae in major curve . } & . & • & . 5 \\
\hline Average age at & diagnosis & . & . & . & . & . 15 months \\
\hline \multicolumn{7}{|c|}{ Site of apex of major curve: } \\
\hline T.6-7 . & . & 1 case & T.9-10 & . & . & 2 cases \\
\hline T.8 & . & 6 cases & T.10 & . & . & 1 case \\
\hline T.8-9 & . & 7 cases & T.11 & . & . & 1 case \\
\hline T.9 & . & 9 cases & T.12 & . & . & 1 case \\
\hline \multicolumn{7}{|c|}{ Apex of curve was at T.8, T.8-9, T.9 in 23 of 28 cases ( 78 per cent) } \\
\hline
\end{tabular}

in which girls are affected more commonly than boys in the ratio of seven to three. James (1951) found that boys outnumbered girls by two to one. 2) The curve pattern is almost exclusively thoracic. After the age of two only one-third of all significant curves are thoracic. 3) The apex of the curve is to the left in $\mathbf{9 3}$ per cent of patients, whereas in thoracic scoliosis occurring after the age of two the apex is to the right in 85 per cent.

vol. 37 B, No. 3, AUGUSt 1955 
Individually these differences may be of little significance, but collectively they are striking, and they tend to confirm that infantile idiopathic scoliosis is distinct from scoliosis starting after the age of two.

Progression-In considering the rate of progression of a scoliosis it is convenient to use graphic analysis. The measurement of the major curve is plotted on the vertical axis, against

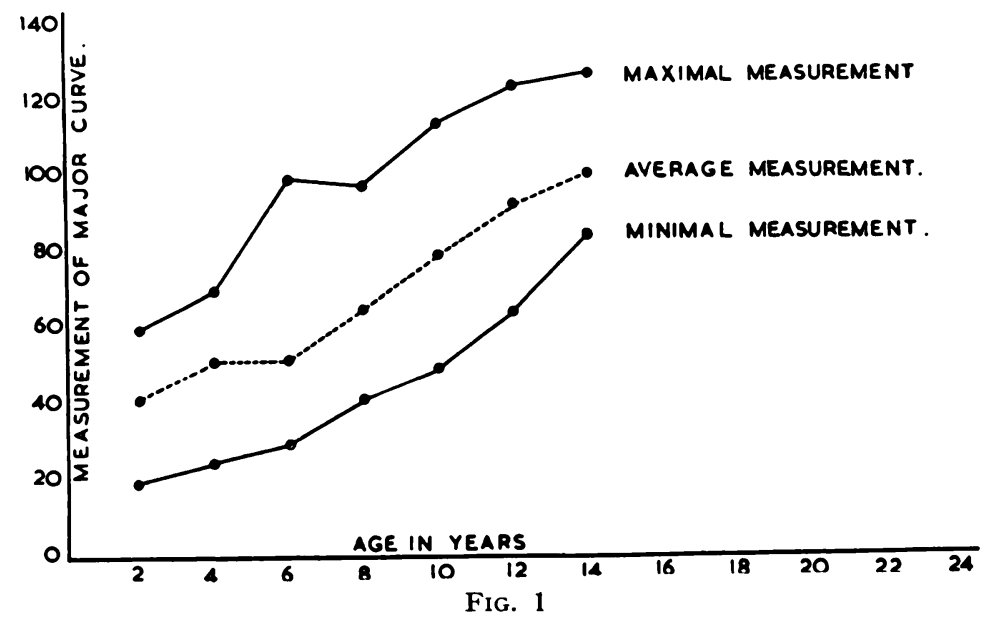

Graph showing the greatest, least and average major curve measurements in twenty-eight cases of progressive idiopathic scoliosis between the ages of two and fourteen.

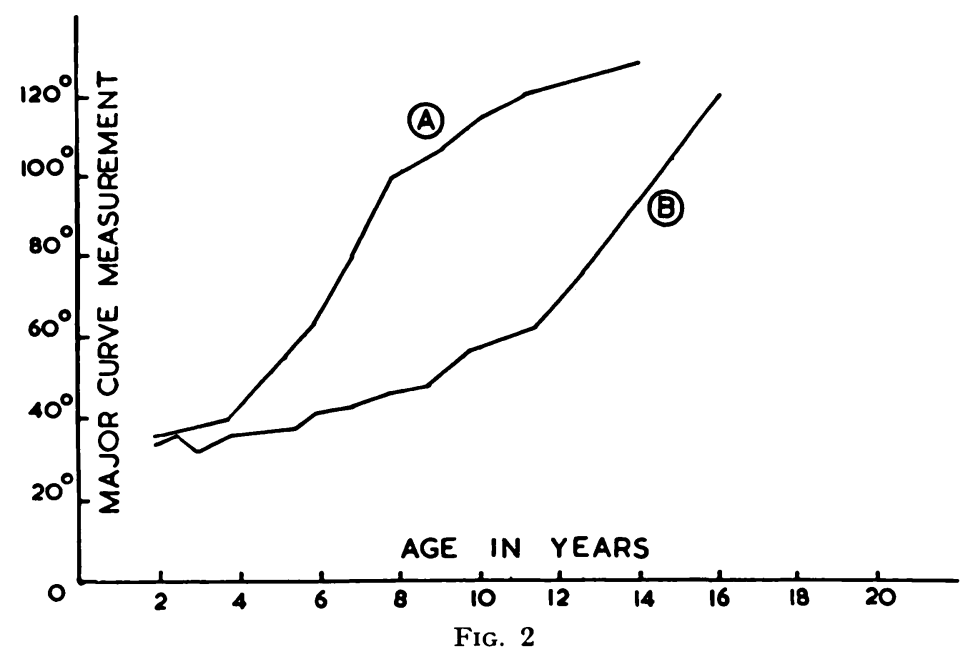

Progression graphs of two infantile idiopathic curves, (A) with early onset of deterioration, and (B) with delayed onset.

the age of the patient on the horizontal axis. These graphs are of great value because they give an immediate picture of the progress of the patient.

A composite graph representing the progression of the twenty-eight patients has been constructed. It shows the greatest and least measurements of all curves at a particular age; and from the statistical analysis we have determined an average progression graph of all our patients between the age of two and fourteen years (Fig. 1).

The composite progression graph seems to demonstrate that, on average, a patient with infantile idiopathic scoliosis with an initial curve of 30 degrees will deteriorate by about 5 degrees per year and that at the age of fourteen a major curve of about 100 degrees can be expected. But from the analysis of individual cases it seems that there is considerable 


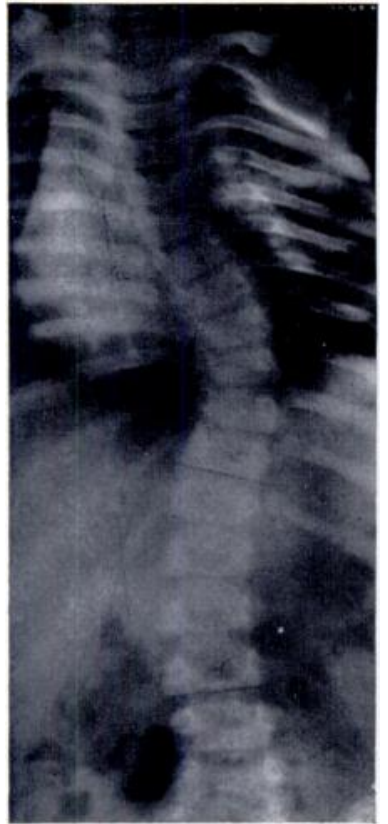

Fig. 3

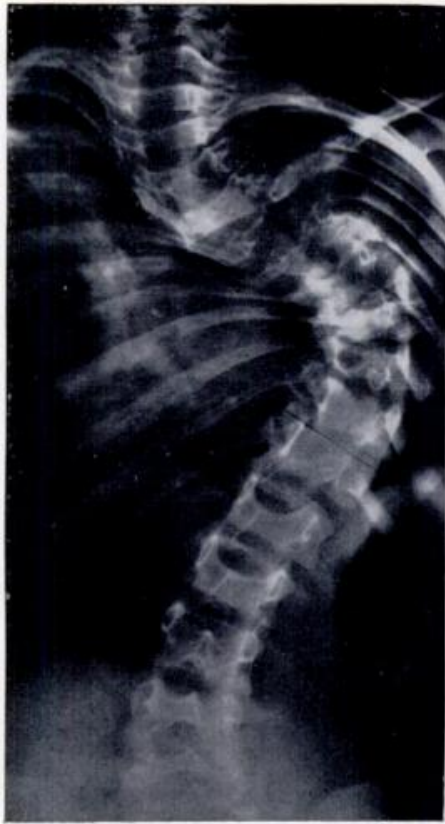

FIG. 4

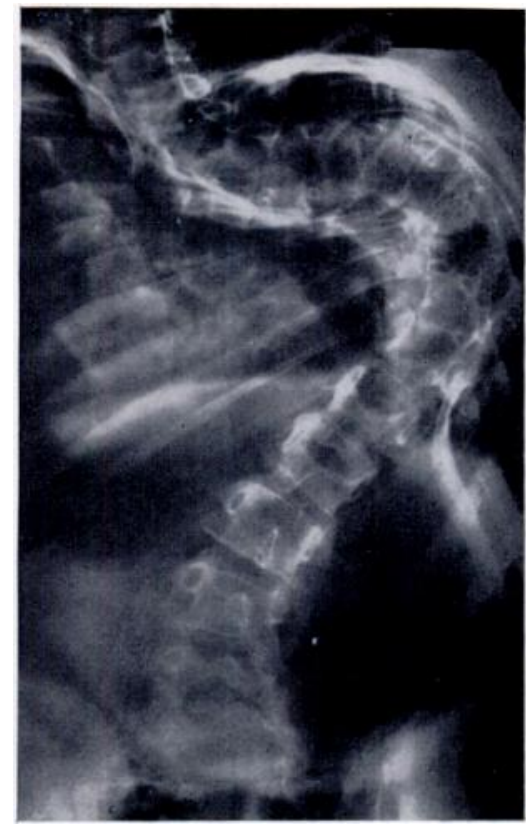

FIG. 5

Radiographs of patient (A) in Figure 2. Figure 3-at age two years. Figure 4-At age eight year:;. Figure 5-At age thirteen years.

variation in the age at which deterioration starts, as distinct from the age at which the curve is first recognised. Deterioration may take place rapidly and continuously from the age of onset, or the curve may remain stationary for several years before deterioration starts. During this quiescent period there may be minor fluctuations in curve measurements, due to the mobility of the curve in young children and to error in curve measurement (Figs. 2 to 9).

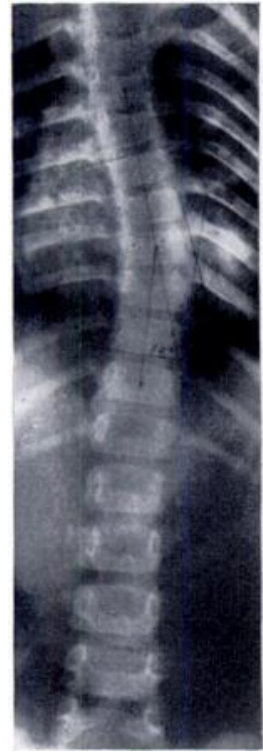

FIG. 6

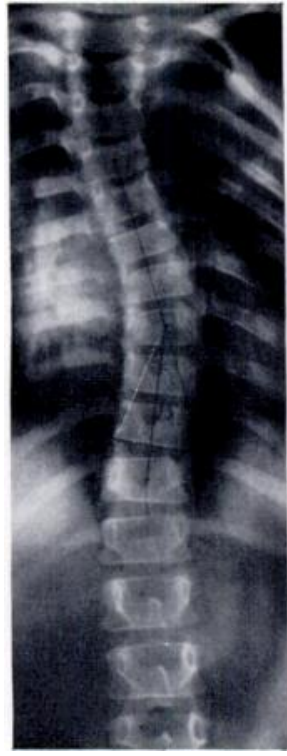

FIG. 7

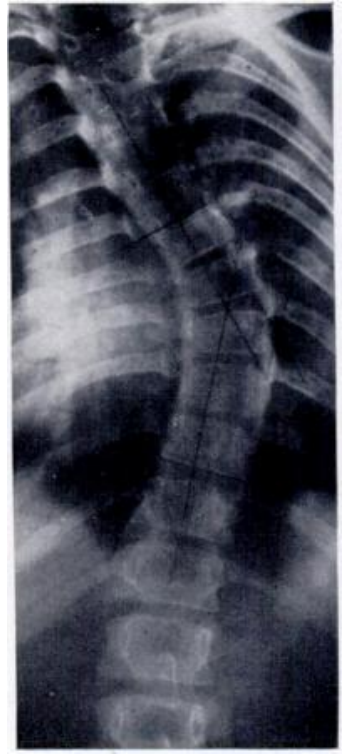

FIG. 8

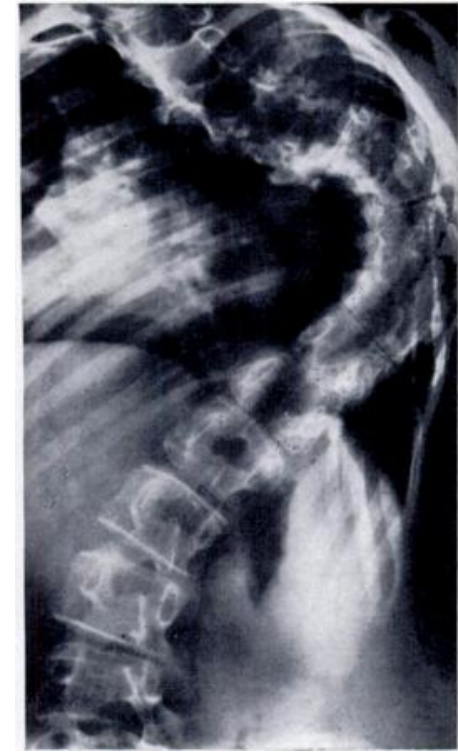

FIG. 9

Radiographs of patient (B) in Figure 2. Figure 6-At age two and a half years. Figure 7-At age six. Figure 8-At age ten. Figure 9-At age sixteen. No deterioration has occurred between the ages of two and six. Despite this delayed onset the final deformity resembles that of patient (A) (Figs. 3 to 5).

VOL. $37 \mathrm{~B}$, No. 3, AUGUSt 1955 
At whatever age the major curve starts to increase, the rate of progression remains fairly constant until growth ceases, though in some cases, with deterioration from an early age, the greatest deformity may be reached even before the end of the growth period. In most patients there is further slight deterioration up to the age of twenty, possibly from secondary bone moulding.

Fourteen patients have been followed to maturity, by which time all had severe deformities with the curves measuring an average of 1:20 degrees. The smallest curve measurement in an untreated patient was 84 degrees at the age of eighteen; by the age of twenty-seven this had become 96 degrees (Figs. 10 and 11 ).

Of the remaining fourteen patients who have not yet reached maturity, many have severe deformities. At the age of six the average curve measurement is 65 degrees, including five children with curves over 80 degrees, the greatest being 112 degrees (Figs. 12 to 14). With one exception the curves appear to be progressing in the manner described. The

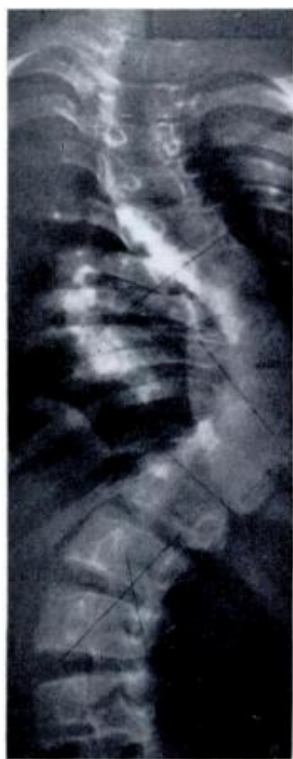

Fig. 10

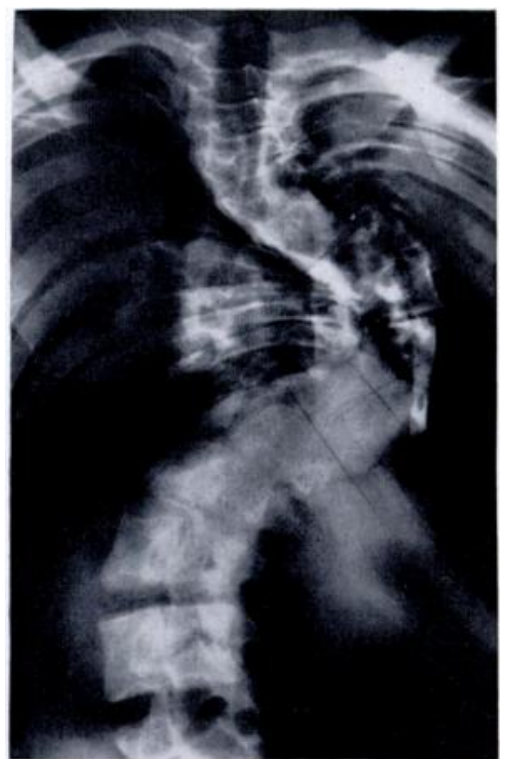

FIG. 11

Intreated progressive infantile idiopathic scoliosis. Radiographs taken at age eighteen (Fig. 10) and at age twenty-seven (Fig. 11). Note the deterioration even after the age of eighteen.

exception is a child who at the age of one year had a 20 degrees' curve; at four and a half years the curve measured 45) degrees and presented the typical appearance of progressive infantile idiopathic scoliosis. This child is now nine years old, and during the past four years no deterioration has occurred; in fact the curve measurement is a few degrees less. This curve appears to be truly non-progressive. It is still possible that further deterioration will take place; but as the boy's height has increased about $3 \frac{1}{2}$ inches in the past twenty months this seems unlikely (Figs. 15 to 17).

The clinical picture - Although radiographic analysis offers a convenient method of observing the progression of a curve, it helps less in the assessment of the patient: this must be done by careful clinical examination, for among different patients there is considerable variation in the deformity, particularly in the shape and size of the thorax relative to the rest of the body. The spinal deformity when fully developed may vary from what is essentially a kyphosis with little lateral curve or rib distortion, to a severe lateral curvature with little kyphosis and gross rib deformity, producing the classical " keel" or " razor" back. In most, the 
thoracic cage is small, with serious reduction in vital capacity. Occasionally, despite a severe curve, the thorax is well developed, and the patient able to lead a normal life (Figs. 18 and 19).

The main factors in these clinical variations are: 1) the length of the major curve;

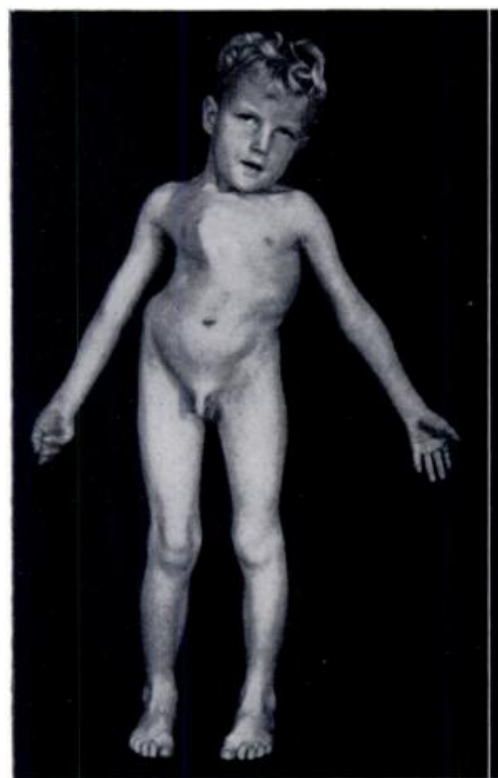

FIG. 12

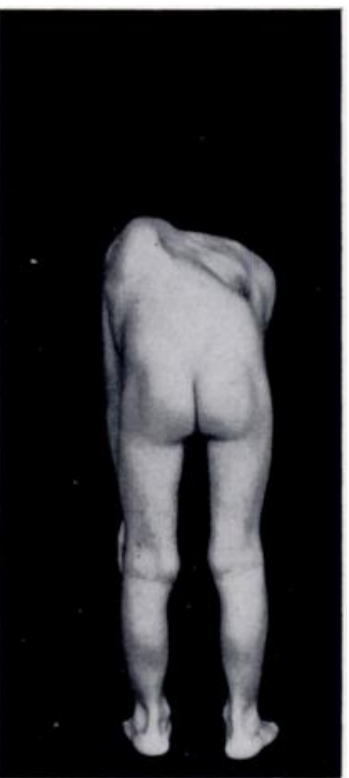

FIG. 13

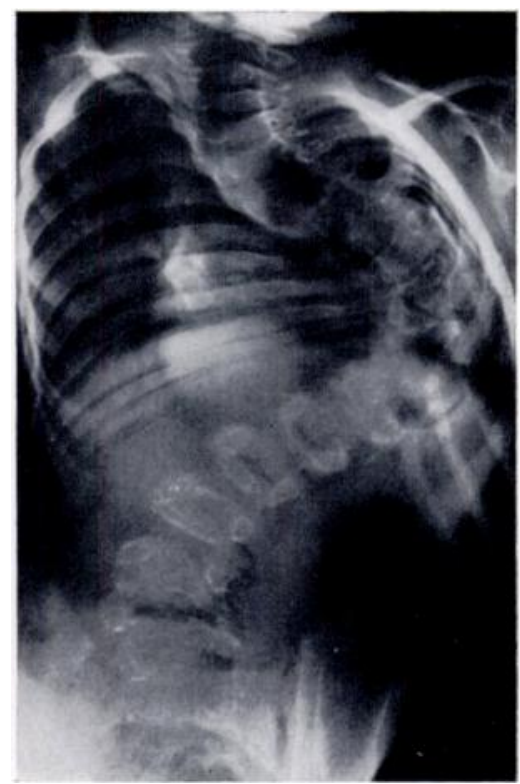

Fig. 14

Progressive infantile idiopathic scoliosis with a severe curve measuring 112 degrees at the age of six years.

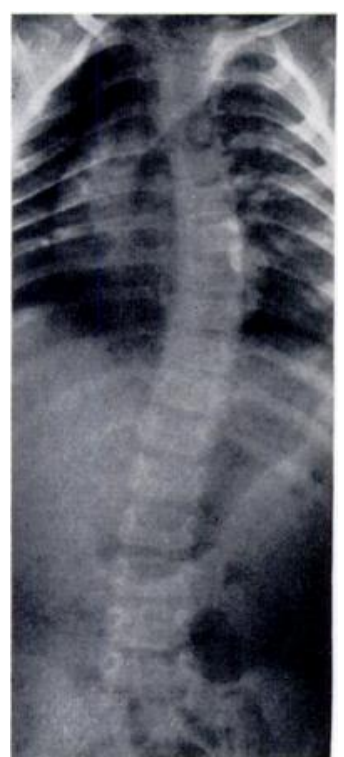

FIG. 15

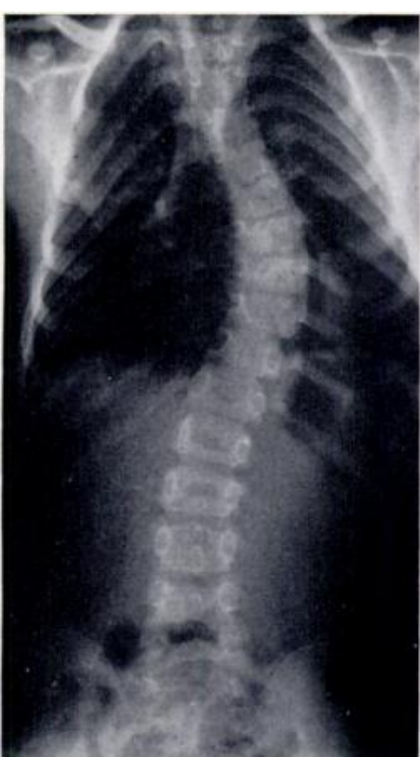

FIG. 16

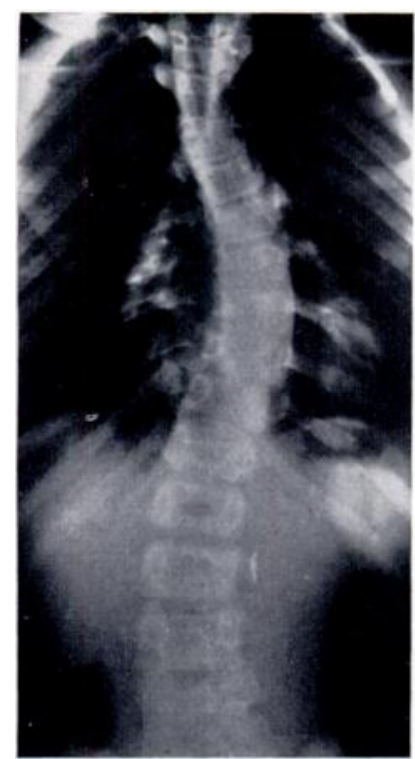

FIG. 17

Con-progressive infantile idiopathic scoliosis-the only one in the series. Figure 15 - At age one year. Figure 16-At age four and a half. Figure 17-At age nine and a half.

2) the degree of rotation of the vertebrae at the apex of the curve; 3) the age at which deterioration starts; and 4) the rate of deterioration. These factors appear to be to some extent interrelated. For instance, the degree of vertebral rotation is usually more severe

vol. $37 \mathrm{~B}$, No. 3, AUGU'St 1955 
in short curves, and these tend to progress from an early age. But, while the rate of deterioration varies, it does not appear to be influenced by the age at which deterioration starts. It is not possible to isolate any single factor as mainly responsible in determining prognosis; but in general the type of deformity is determined by the length of the curve and degree of rotation, and the severity by the age of onset of progression and the rate; both these factors influence the degree of disability and therefore the prognosis.

The shortest curve in this series consisted of three vertebrae, and from the earliest radiographs it was evident that, despite a comparatively slight lateral curve, there was pronounced rotation of the affected vertebrae (Figs. 20 to $\mathbf{2 \cdot \mathbf { 2 }}$ ). As the curve progressed

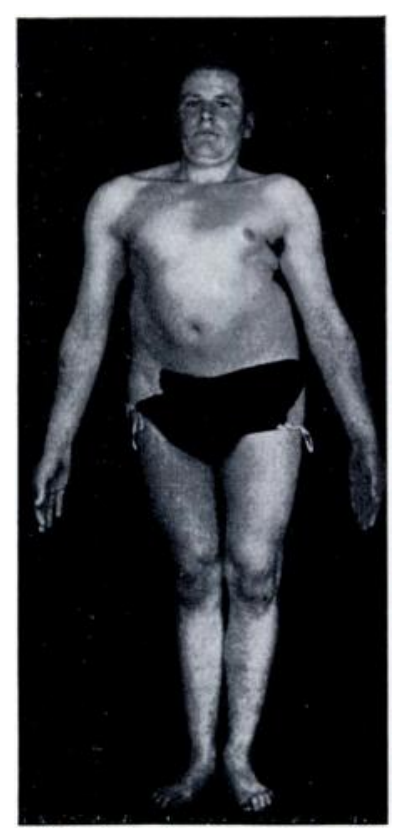

FIG. 18

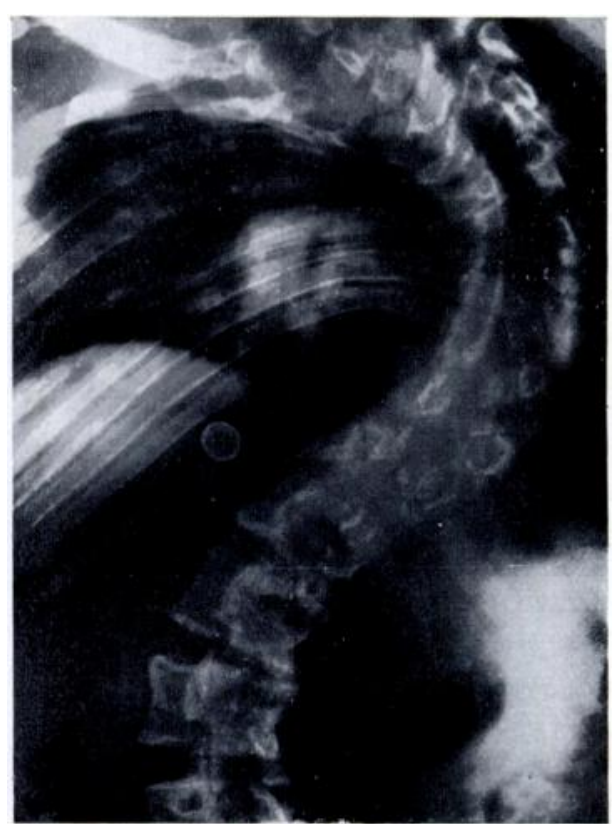

FIG. 19

Progressive infantile idiopathic scoliosis. Patient aged twenty-five. Despite the severe curve the thorax is well developed. This is one of the longest curves in the series.

a kyphosis (of 125) degrees) developed and, although extreme vertebral rotation was visible on the radiographs, there was no significant unilateral rib hump. In the light of our present knowledge of the production of these deformities, we can only speculate on the pathological process involved; it may be that rotation is sufficiently severe to cause a lateral subluxation of the vertebral bodies at the apex of the curve, with consequent forward collapse of the spine above the lesion (Figs. 23 to 25 ).

In patients with long curves the total rotation deformity may be equal to that in a short curve but it is more widely distributed. As the deformity progresses a lateral curvature develops, and, though the rotational element increases, a long segment of the spine is involved, and little or no forward collapse occurs. With the relative absence of kyphosis rotation of the vertebral segment produces the classical rib deformity (Fig. 26). In most patients five vertebrae were involved and the deformity was a mixture of the two patterns described above (Fig. 27).

Disability - The greatest functional disability in this type of scoliosis arises from the thoracic deformity. The vital capacity is reduced; and cardiovascular function is impaired by the distortion and diminution in size of the thorax, and the increased fixation of the ribs. The deformity is usually worse in patients with an early onset of deterioration, for, in these, as well 
as the disproportion of the thorax, the whole body may be underdeveloped, presumably because of a generalised failure of growth. In patients with a later onset of deterioration and slower rate of progression, milder deformity may occur, producing little or no functional disability.

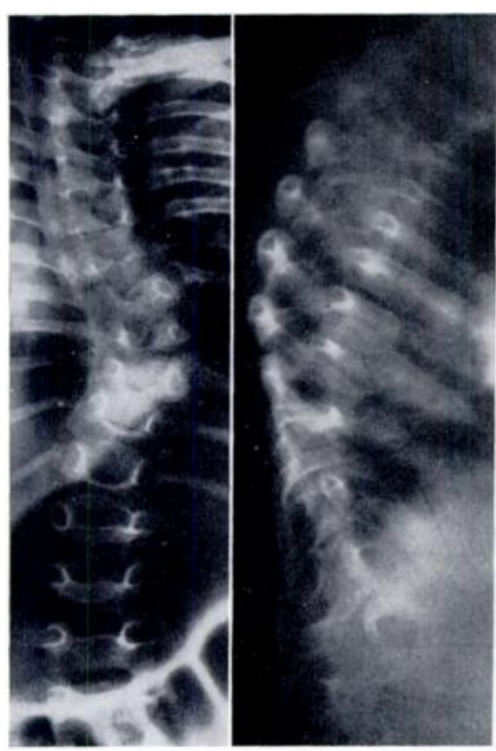

FIG. 20

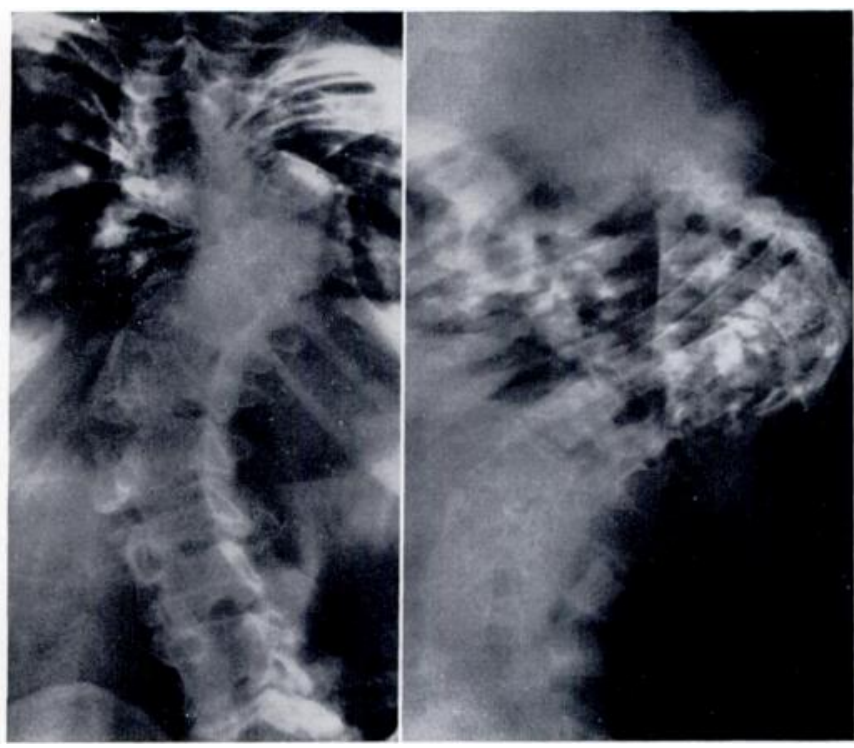

FIG. 21

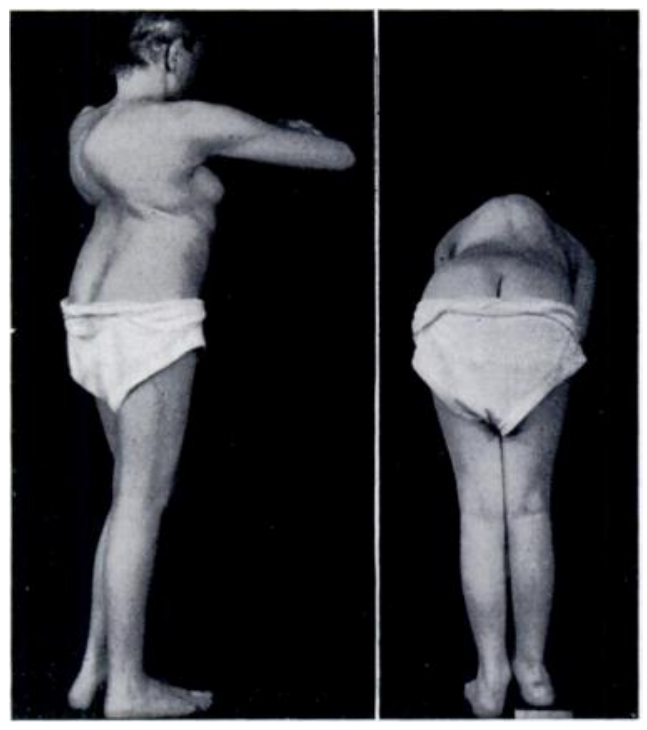

FIG. 22

Progressive infantile idiopathic scoliosis with short curve. Figure 20 shows antero-posterior and lateral radiographs at the age of three vears. Figure 21 shows antero-posterior and lateral radiographs at age twent $y$-four and the photographs in Figure 22 were taken at the same age. In the early lateral radiograph the kiphotic element is minimal. The radiographic appearance of the spine in the later antero-posterior film is due to the severity of the kyphosis, and is typical of this type of progressive infantile scoliosis.

The cosmetic disability is usually severe and depends on decompensation and rib distortion. The degree of rotation and of kyphosis is often as great a factor as the lateral curvature. Decompensation is by no means a constant finding, as adequate compensation often occurs in the minor curves, both above and below the major curve (Fig. 28).

vol. $37 \mathrm{~B}$, No. 3, ALGC'st 1955 


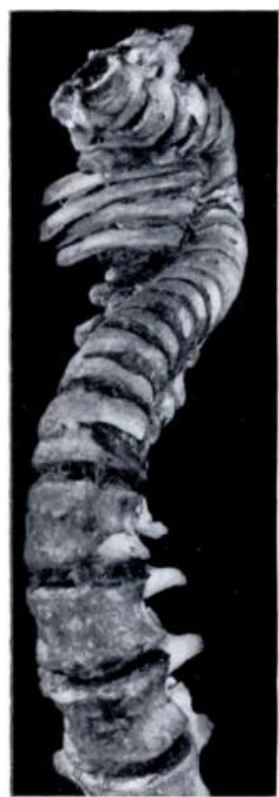

Fig. 23

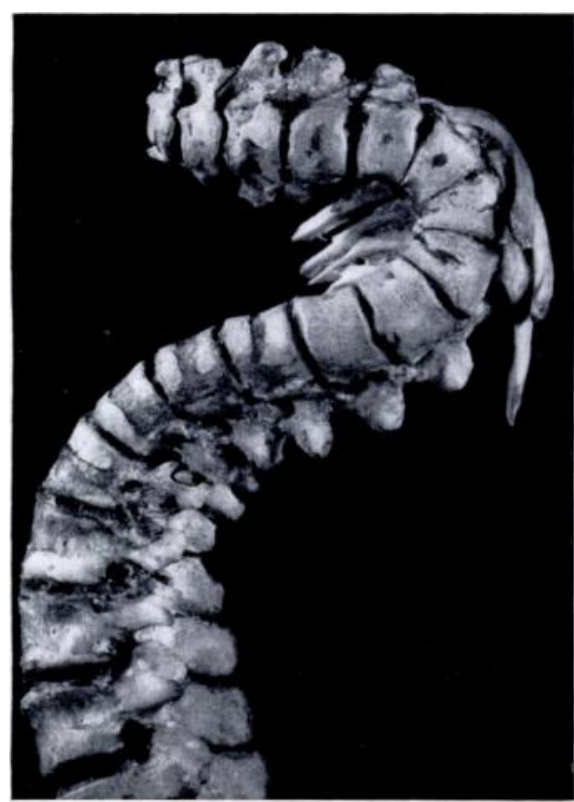

FIG. 24

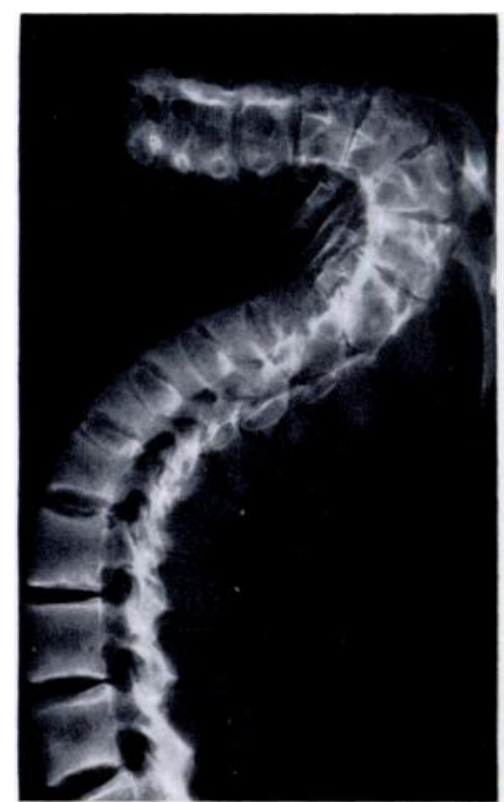

FIG. 25

A post-mortem study of a kyphoscoliotic spine. Figure 23-Antero-posterior view. Figure 24-Lateral view. Figure 25-Radiograph of the specimen. These illustrations demonstrate the term forward collapse, showing the relationship of the spine above the major curve to the column below it. Note that at the apex of the curve there is vertebral rotation through 90 degrees, and that in this area of the spine the deformity is one of lateral curvature.

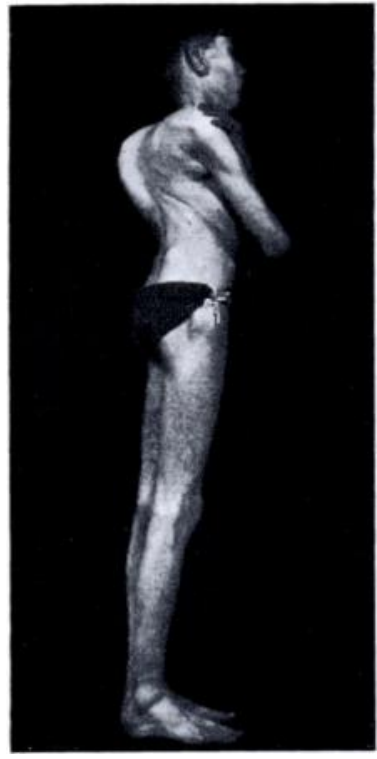

FIG. 26

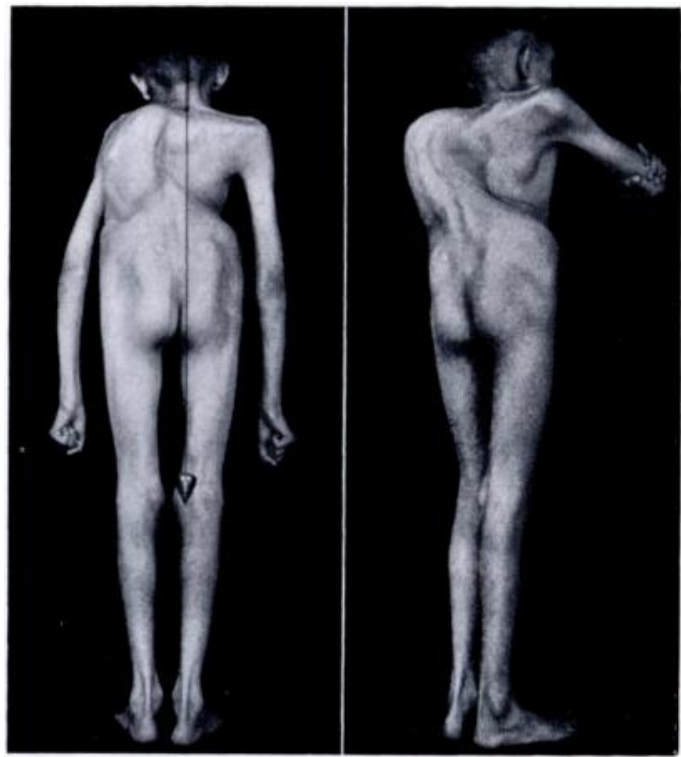

FIG. 27

Figure 26-Oblique photograph showing severe rib hump, with only slight increase in the normal curvature of the throacic spine. Figure 27 - Patient aged thirteen with typical kyphoscoliosis. Despite the severe curve there is little decompensation. The thoracic deformity is severe because of the early onset of deterioration. The radiographs of this patient are shown in Figures 3 to 5. 
Pain, an unusual symptom in the developing curve, is relatively common later in life and may be due to a variety of causes. These include root compression, pressure of ribs on the iliac crest, and secondary degenerative arthritis. Four of the eleven surviving patients who had reached maturity were considered to have no significant functional disability.

Mortality - There have been four deaths in the twentyeight patients, a mortality of 14 per cent. One death followed a spine fusion operation at the age of seven, and was due to mesenteric thrombosis; the remaining three deaths - at the ages of seventeen, twenty and twentynine-were due to pulmonary and cardiac conditions for which the thoracic deformity could be held directly responsible.

FIG. 28

Radiograph of a patient aged thirteen showing satisfactory compensation in the secondary curves. In this case most of the compensation is occurring above the major curve.

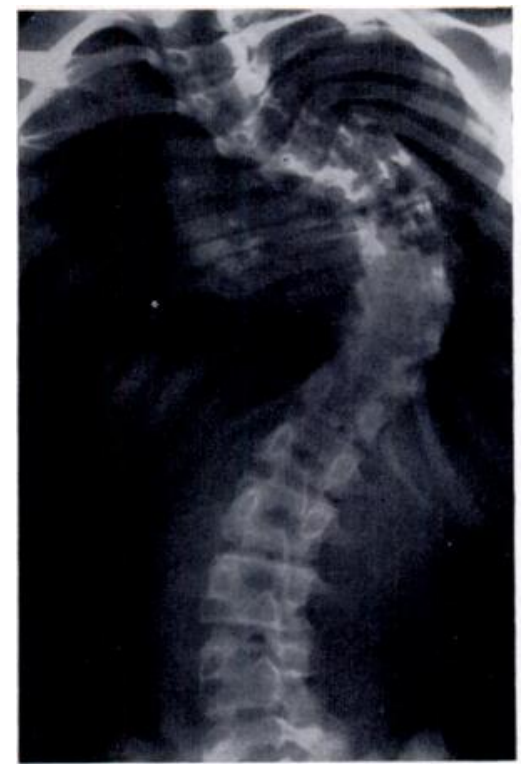

FIG. 28

RESOLVING INFANTILE IDIOPATHIC SCOLIOSIS

Seven patients with resolving scoliosis are included in this review. This condition is probably more common than this number would suggest; but, because the deformity becomes less apparent as the infant gets older, many may not be brought for advice. This group is worthy of consideration because of the importance of differentiating it from the progressive group with regard to prognosis; and the fact that a marked curvature can exist, even for several years, and then spontaneously resolve, is of interest when considering the pathology of scoliosis. The existence of this type of infantile scoliosis may account for the successful results in the treatment of infantile scoliosis reported by Harrenstein.

The seven cases of resolving infantile scoliosis encountered in this series are analysed in Table III.

Two types of resolving infantile idiopathic scoliosis can be recognised, although probably the distinction is of interest only because of its possible bearing on the etiology: Type 1-The curve is shown to diminish gradually in successive radiographs until the spine is normal (Figs. 29) and 30). Type - The curve remains stationary, or even gets slightly worse for two or three years, and then (quite suddenly disappears within a few months (Figs. 31 to 333).

The longest interval between the discovery of the scoliosis and the spine's becoming straight both clinically and radiologically was four and a half years, and the average time for the seven patients was two and a half years.

\section{DIFFERENTIAL DIAGNOSIS}

Classification -Scoliosis may be classified as follows: 1) Congenital abnormalities. 2) Scoliosis of known etiology: paralytic; thoracogenic; neurofibromatosis and other neurological conditions. 3) Scoliosis of unknown etiology (idiopathic): progressive; resolving.

In considering the differential diagnosis of scoliosis in the infantile group the problem is simplified by the natural exclusion of scoliosis of known etiology. Paralytic scoliosis before the age of two is uncommon, and the symptomatology is usually sufficiently evident to establish the diagnosis.

vol. 37 B, No. 3, August 1955 


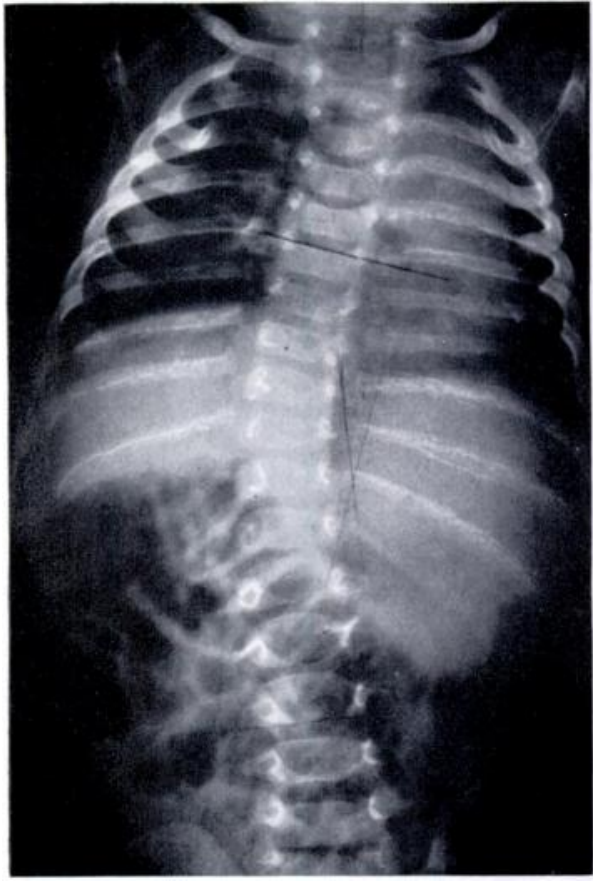

FIG. 29

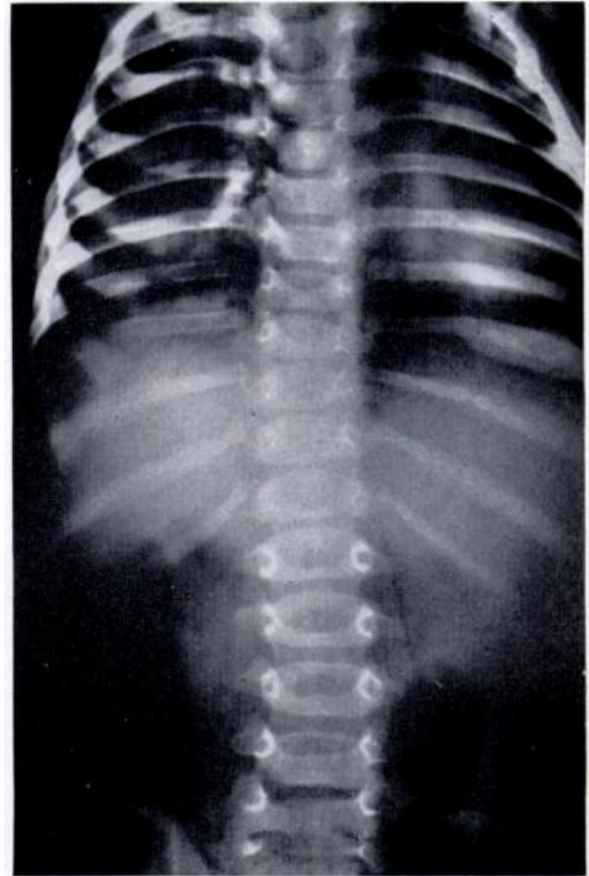

FIG. 30

Resolving infantile idiopathic scoliosis, type 1. Figure 29-Radiograph at age five months. Figure 30-At age thirteen months. The apical rotation clearly visible in the early radiograph is shown corrected in the later film.

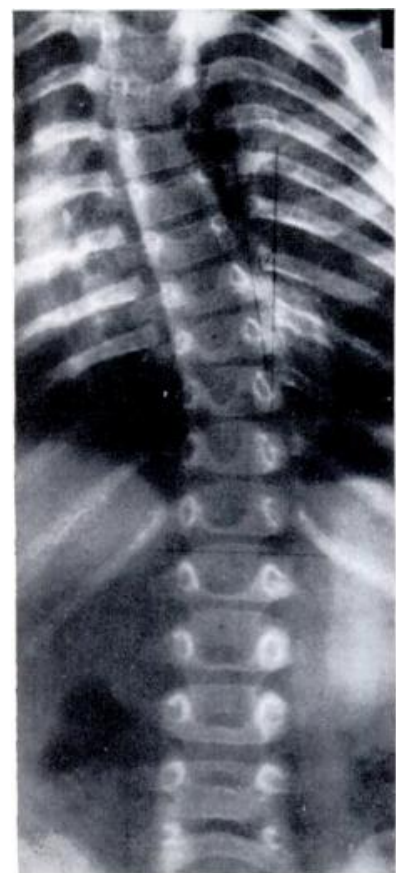

FIG. 31

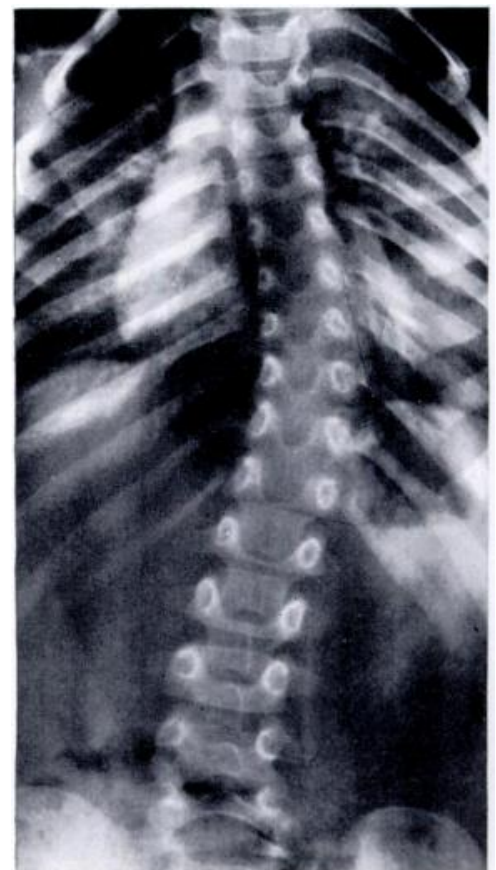

FIG. 32

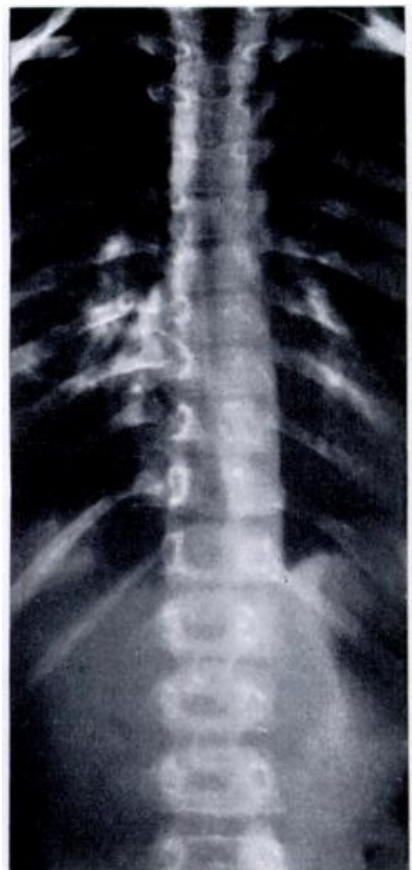

FIG. 33

Resolving infantile idiopathic scoliosis, type 2. Figure 31 -Radiograph at age one and a half years. Figure 32-At age three years. Figure 33-At age six and a half years. This patient had no treatment. 
Likewise, scoliosis associated with neurofibromatosis is unusual at this early age. The earliest age at which a curve was observed in a patient having, or subsequently developing, other stigmata of the disease was seven years, although undoubtedly the curve had been present before this. The similarity of deformity, both clinically and radiographically, between the scoliosis of neurofibromatosis and the kyphotic type of infantile idiopathic scoliosis must cause serious consideration of whether, in fact, they represent minor variants of the same

TABLE III

Analysis of Seven Cases of Resolving Infantile Scoliosis

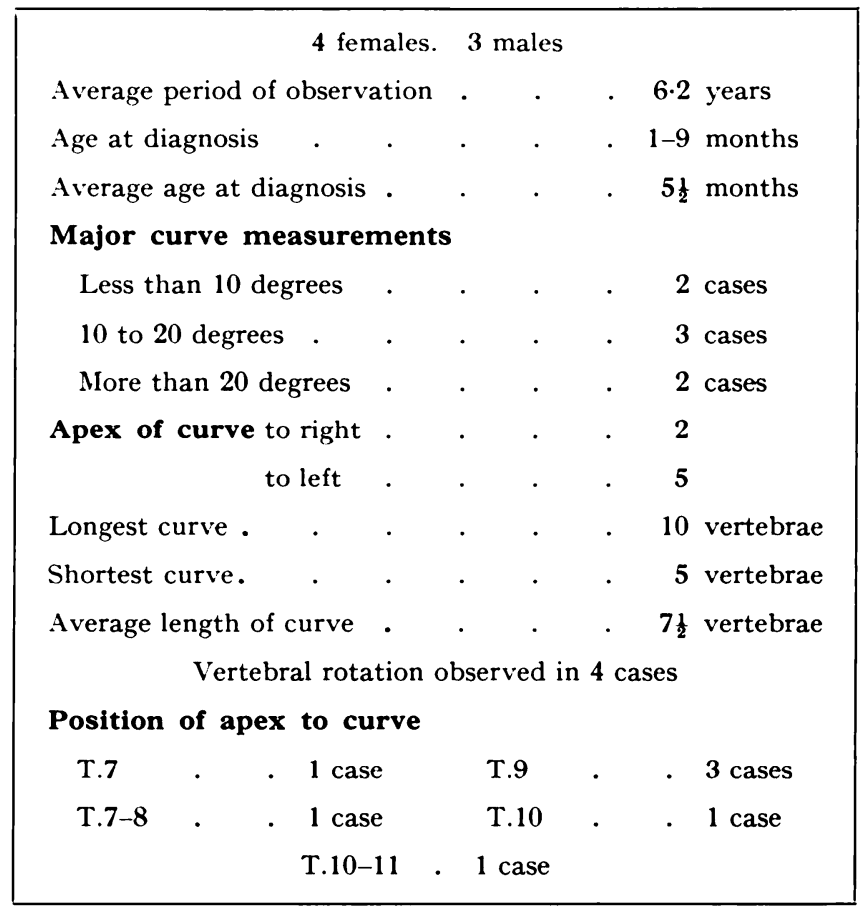

TABLE IV

Differential Diagnosis of Progressive and Resolving Infantile Idiopathic Scoliosis

\begin{tabular}{|c|c|c|}
\hline & Progressive & Resolving \\
\hline Average age at diagnosis. & 15 months & $5 \frac{1}{2}$ months \\
\hline Average number of vertebrae in major curve & 5 & $7 \frac{1}{2}$ \\
\hline Major curve measurement & More than 20 degrees & Usually less than 20 degrees \\
\hline Degree of rotation of apical vertebrae & Usually marked & Minimal \\
\hline
\end{tabular}

disease. We have no evidence at present of neurofibromatosis in any patient of this series; but this does not necessarily preclude its later appearance (Figs. 34 to 36 ).

Scoliosis secondary to congenital spinal abnormalities is relatively common, and during the period covered by this review, forty-two patients with congenital scoliosis have been treated at this hospital, representing 15 per cent of all those with progressive curves. The average age at diagnosis in this group was eleven years, and in only seven infants was the curve noticed before the age of one year. The diagnosis of congenital scoliosis is made from radiographs in which the defects are clearly visible in infancy and adolescence (Fig. 37).

vol. 37 B, No. 3, AUGUSt 1955 
In later life the radiographic appearances tend to be confusing because of secondary structural changes, and it may be difficult to distinguish a congenital from an idiopathic scoliosis.

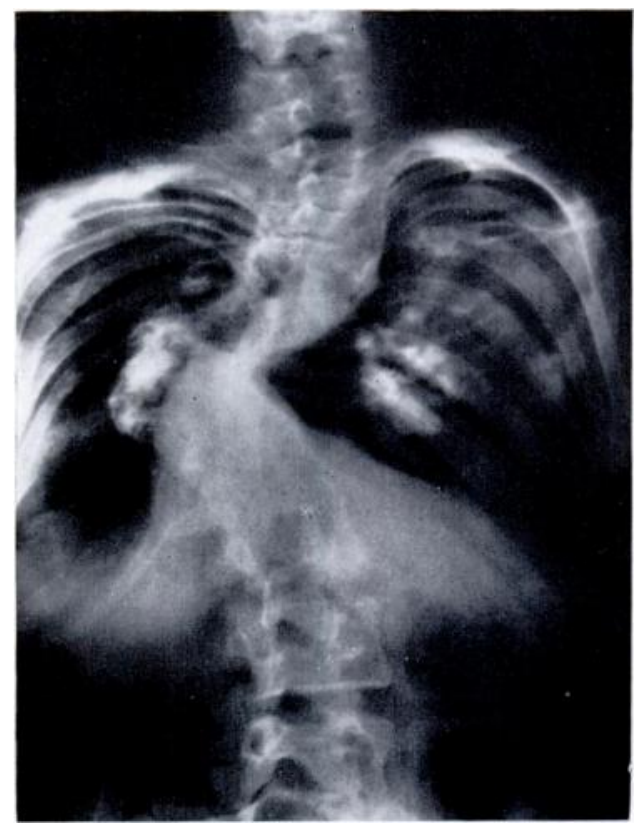

FIG. 34

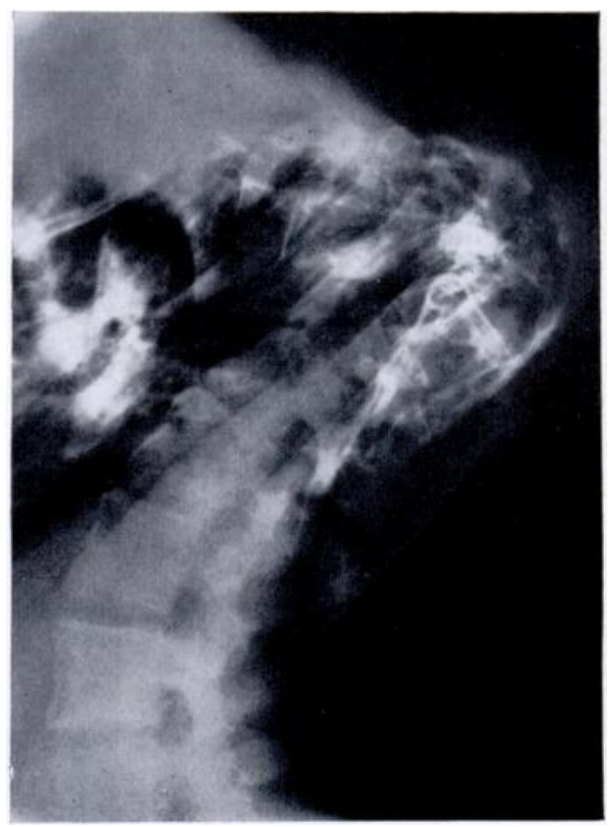

FIG. 35

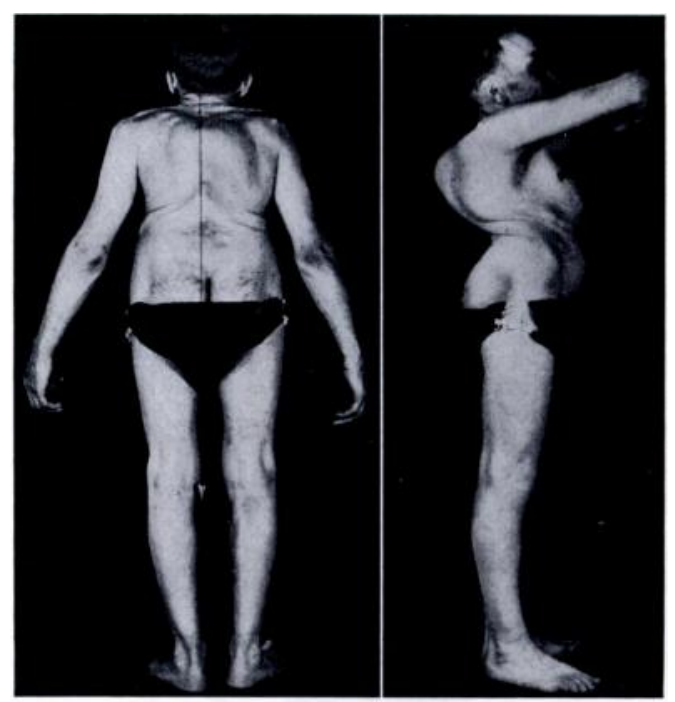

FIG. 36

Scoliosis associated with subcutaneous neurofibromatous nodules. Figure 34-Anteroposterior radiograph. Figure 35-Lateral radiograph. Note the similarity of the deformity and radiographic appearance with the kyphotic type of progressive infantile idiopathic scoliosis (see Figs. 20 to 22).

Conversely, in a long-standing severe idiopathic curvature secondary effects occur, such as fusion of the laminae, which may lead to the erroneous diagnosis of congenital scoliosis.

In this series of twenty-eight cases of infantile idiopathic scoliosis there was no evidence of congenital defects of the thoracic spine. It has been suggested that congenital abnormalities may be present in these curves but insufficiently severe to be seen on radiographs. 
The average rate of progression of congenital scoliosis is much below that of progressive infantile idiopathic scoliosis. In forty-two cases of congenital scoliosis analysed the average

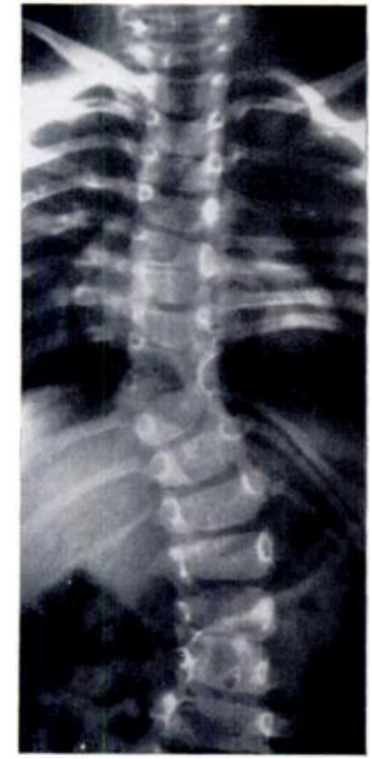

FIG. 37

Radiograph showing typical congenital abnormalities. The hemivertebra, rib defects and fusion of laminae are clearly visible, and prevent confusion with idiopathic scoliosis.

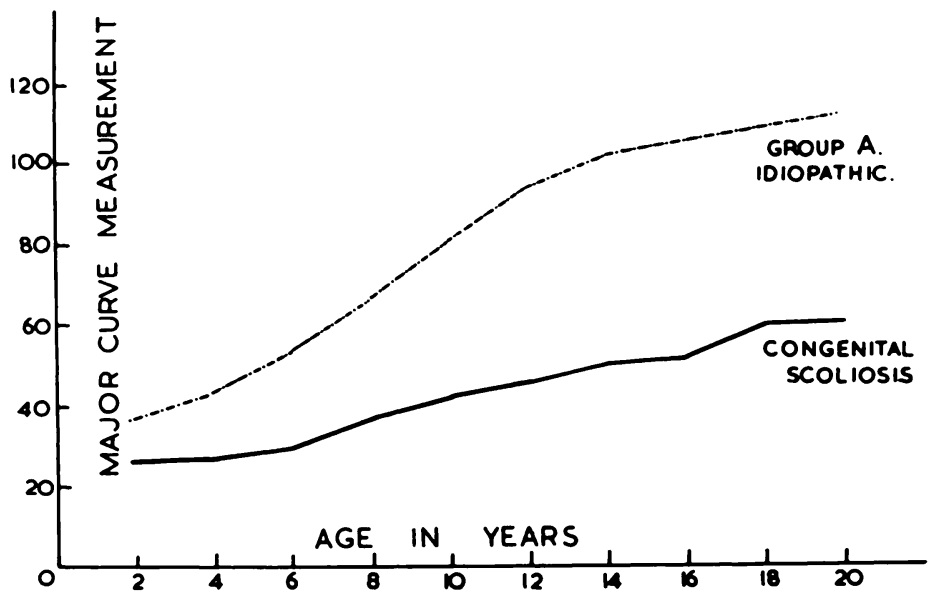

FIG. 38

Graph showing the average progression of known cases of congenital scoliosis (forty-two cases), compared with that of progressive infantile idiopathic scoliosis.

rate of progression was 2 degrees a year, compared with :) degrees in progressive infantile idiopathic scoliosis (Fig. 38). This significant difference suggests that infantile idiopathic scoliosis is a separate entity from congenital scoliosis. With the exclusion of congenital scoliosis and scoliosis of known etiology, the differential diagnosis remains between progressive and resolving idiopathic scoliosis: this may be difficult and the diagnosis may be in doubt up to the age of three years. There are, however, some points that may help in differentiating these two types (Table IV).

SUMMARY

1. The natural history and prognosis of progressive infantile idiopathic scoliosis are reviewed and twenty-eight cases are reported.

2. Resolving infantile idiopathic scoliosis is described and seven cases are reported.

3. The length of the curve, the degree of rotation, the age of onset of deterioration, and the rate of progression are the important factors in determining the type and severity of the deformity. 4. Infantile idiopathic scoliosis is briefly compared with congenital scoliosis.

We wish to thank all members of the Staff of the Wingfield, who by their agreement to the continued concentration of all patients with scoliosis have made the long-term review of the subject possible, and in particular Professor Trueta for many helpful suggestions. We also wish to acknowledge the help and inspiration of the late $\operatorname{Mr}(i$. R. Girdlestone who made possible the commencement of this study. We are also indebted to Miss Robins of the X-ray Department, and Miss Bird, Clinical Photographer, for their help and co-operation.

\section{RFFERENCES}

American Orthopaedic Association Research Commitee (1941): End-Result Study of the Treatment of Idiopathic Scoliosis. Journal of Bone and Joint Surgery, 23, 963.

Harrenstein, R. J. (1936): Sur la Scoliose des Nourrissons et des Jeunes Enfants. Revue d'Orthopédie, 43 ann., 3 sér. t. 23, 289.

James, J. I. P. (1951): Two Curve Patterns in Idiopathic Structural Scoliosis. Journal of Bone and Joint Surgery, $33-\mathbf{B}, 399$

JAMEs, J. I. P. (1954): Idiopathic Scoliosis: the Prognosis, Diagnosis, and Operative Indications Related to Curve Patterns and the Age at Onset. Journal of Bone and Joint Surgery, 36-B, 36.

Ponseti, I. Y., and Friedman, B. (1950): Prognosis in Idiopathic Scoliosis. Journal of Bone and Joint Surgery, 32-A, 381.

Vol. 37 B, No. 3, AUgust 1955 